\title{
Management of Looses Supported from Master Data Cleaning Process, for OSHEE Distribution Sector
}

\author{
Dr. Anni Dasho \\ European University of Tirana, Economic and Information Technology Faculty, \\ Information Technology, Maths and Statistic Department \\ anni.dasho@uet.edu.al \\ Eng. Diana Sharra \\ Management of Looses Projects Expert., OSHEE (Albanian Power Distribution System) \\ Dr. Genci Sharko \\ Faculty of Electric Engineering, Polytechnic University of Tirana, Republic of Albania \\ gsharko@gmail.com \\ Prof. Asoc. Dr. Indrit Baholli \\ Lecturer, Faculty of Economy, European University of Tirana \\ indrit.baholli@uet.edu.al
}

Doi:10.5901/ajis.2015.v4n2p129

\begin{abstract}
Since CEZ time, the OSHEE Company has been involved in some regulatory discussions with ERE that had prevented the company from implementing a proper and comprehensive loss reduction plan in years. Nevertheless the OSHEE Company has start end of 2014 several initiatives for the loss reduction that, in staff's words, may lack of the proper comprehensiveness and/or high-level view to be absolutely successful. International experience shows that Albanian's case seems similar to the Latin American cases in 90's and 2000's. High loss levels with a population with a low interest in paying the electricity and a soft social and punitive framework that somehow allows irregular consumption of the energy. Even in these cases, being the energy losses a sector and country's problem, solutions have been found and implemented with the necessary strong and consistent efforts and support of all involved stakeholders within a comprehensive loss reduction framework. The initiative to create a pilot project for: - Checking OSHEE ability to clean the customer database with in house resources. - Checking OSHEE's ability to conduct network mapping task with in house resources. - Checking OSHEE's ability to perform improvement of network and measurement installations condition without major investments. - Testing new operational approaches. - Understanding major obstacles for loss reduction efforts.
\end{abstract}

Keywords: Energy losses, Billing System, Network Mapping etc...

\section{Introduction}

OSHEE(Albanian Power Distribution Company) has significantly reduced energy losses from non payed monthly Bills from Company Clients in years, but in the meantime has depth technical losses in the network from excessive depreciation of the physical network.

From INSTAT analyses, the total quantity produced during 2014 was 4,726 GWh for OSHEE. Electric powerderived from all sources, during 2014 decreased 0.8 percent compared with 2013 . The total quantity of net domestic production and electricity exchange was 7,794 GWh.

The domestic productionof electric power represents 60.6 percent of the total quantity of available electricity, where the total quantity produced during 2014 was 4,726 GWh compared with data from 2013 at the 6,959 GWh level, with a decrease by 32.1 percent.

End of 2013 and during 2014 the main source of electricity generation was the hydropower plants production. The 
quantity of electricity produced by hydropower plants is decreased 32.1 percent compared with data received from 2013. Public hydropower plants production represents 72.1 percent of total domestic production, and here we consider even the independent power producers on the total production of electricity which has been at the level of 27.9 percent.

The Electricity sector in Albania needs to urgently become financially Self-Sustainable.

OSHEE as the Distribution Company has a specific role among the sector's actors for which it gets a compensation:

- To provide the physical support to the distribution of the electricity, and

- To collect the monetary resources for the sustainability of the sector.

Total losses are now beyond reasonable limits and OSHEE has the commitment, provided that there is the support of the whole sector, to reduce the losses to sensible values that make the sector viable.

OSHEE is committed to implement a comprehensive Loss Reduction Plan.

\section{Project Implementation for Management of Losses Finalized with the Data Cleaning Process on Billing System}

Management of losses, especially non-technical losses, on the pilot specified area, by using the existing OSHEE electrician's staff and the minimum materials basis, with the smallest expenses to be dedicated for this pilot project.

\section{Project Methodology Used}

\subsection{Phase 1 - First and Second Billing Cycles (2,5 month)}

- Selection of a feeder with average (not best/not worst) technical conditions, losses, network length, geographic location, number of customers, transformers, balance between commercial and residential customers, historic consumption, not metered customers, etc.

- Assign 2-4 employees $100 \%$ of their time to the pilot project doing the whole process.

- Perform increased number of customers' inspections.

- Replace meters and fix measurement installations (when possible and needed).

- Resolve not metered customers' problem and secure measurement installations.

- Organize network clean-up work.

- Install transformer meters (when possible) for balancing purposes and perform readings.

- Perform network mapping.

- Perform customer data clean-up on the Billing System matched with the real data of the customer location.

- Synchronize data and conclude the master data cleaning process in the billing system.

\subsection{Phase $2-2$ billing cycles (2-2.5 month)}

- Reorganize and conduct meter readings based on new approaches.

- Conduct feeder/transformer/customer balancing based on new approaches.

- Increase number of customer verifications with existing resources, without changing number of assigned personnel.

- Reorganize and conduct disconnections based on new approaches.

- Assign targets for commercial losses and collection to the feeder team.

- Implement performance evaluation system with $100 \%$ precision.

\section{Project Methodology Used}

- First phase had the following sub-phases:

- Analysis and Definitions of Project Phases

- Implementation to be divided in two main Projects 1 and 2.

- Backup Policy of the Data Cleaning Process

- Second phase had the following sub-phases:

- Final preparation (Migration, Integration tests, Documentation, user training) 
- Go Live with the updated final accurate data at the Billing System

\section{Implementation Phases to be Developed}

Implementation- Project 1

First Pilot Project (August-October 2014)

OSHEE used different principles during the implementation:

- The feeders' selection criterion was changed from average feeder, to the feeders with at least number of customers (up to 200-300 customers).

- $\quad$ Network mapping and data cleaning tasks were performed with different approaches.

- Structural changes were applied, but without no changes in operational processes-meter readings, disconnections were conducted in the same way as before.

\section{Results}

- $\quad$ The network clean up and mapping tasks were completed (not with high quality).

- $\quad$ No progress in: customers' inspection, measurement installations' protection, fixing, replacement and network clean up directions.

- No progress in changing the existing operations and consequently no results in the loss reduction.

Implementation - Project 2

Second Pilot Project (November 2014 - February 2015)

OSHEE top management level agreed on proposed principles:

- $\quad$ The assigned employees (2 persons) were not available during the project implementation for 17 (22\%) days.

- $\quad$ The feeder team leader is working only for $50 \%$ of the time.

Problems-Difficulties

- $\quad$ Meters and most part of spare materials were not available.

- Deficit of loss reduction equipment.

- The project team was not working on the project full time.

- Complicated season (including increased consumption, holidays, and weather conditions).

Progress and Results

- Completed nearly 800 customers' inspections, where detected 26 cases of theft, identified 2 illegal consumers.

- Cleaned up the network components and regularized load in some transformer phases (for decreasing technical losses).

- Around 800 customers' collective boxes were cleaned, fixed and locked.

- All technical schemes of the feeder, transformers and LV lines are documented in passports (including schemes, MV and LV lines and other components).

- Following corrections were made in the billing system after completing the cleanup and mapping tasks:

- Number of transformers has changed from 20 to 18 (2 transformers didn't exist, one was moved to different feeder and one was moved from different feeder).

- 1536 customers of this feeder are correctly assigned to the specific transformers and LV lines.

- 107 customers can't be found (so called "closed contracts").

- Customers meter reading was conducted 4 times per month which allowed more dynamic and qualitative control.

\section{Results of Data Cleaning and Mapping Figures on the Management of Losses Process}

Data Cleaning and Mapping figures:

a. Network conditions before and after: 

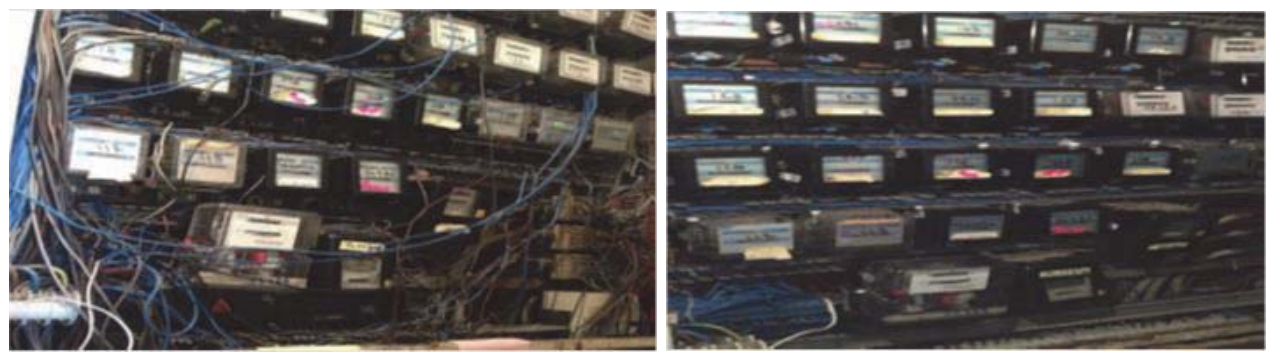

Figure 1. Boxes before and after the project of data cleaning and mapping network process.

From the analyses phase done by OSHEE Management, USAIS Project advising and supporting the management of loses process the whole actors came at the following conclusions comparing data of 2013 vs. 2014:

Feeder losses in November went down to $35 \%$ from $48 \%$ in 2013 (13\% reduction), and $43 \%$ (8\% reduction) in October 2014. The Agency Tirana 1 losses went up from 22,5\% in October to 27\% in November. In December losses made further progress and went down to $32 \%$ against $53.4 \%$ in 2013 (21\% reduction). The pilot feeder was progressing when losses for the entire company were going up from 32.8\% in November to 37, 5\% in December.

Based on existing readings and balances January results will be $30 \%$ or lower. Last year's losses for the same period were 50,5\%(20,5\% targeted reduction). Collection has increased from 5,126,771 LEKE in 2013 to 11,618,694 LEKE in 2014, this is more than double increase.

Definitely, the level of losses in the company is very high even compared to other similar examples. Number of customers billed with energy shows a very low percentage with regards to total number of customers in the billing cycle. Problems respond to different reasons: impossibility to reach the supply point and low quality of the measurement among others.

Energy in selected customers (private + government) shows that almost $50 \%$ of the energy is billed to them. This means that these clients must have problems in the energy registering in order to have a balance of $40-45 \%$ losses. Geographically, the $60 \%$ of the losses are concentrated in Tirana, Durresi and Shkodra. Areas that also concentrate $60 \%$ of the Energy.

Additionally, the company has been growing at a rate of $5 \%$ every year on average for the past 3 years. This fact has also affected the level of technical losses in a grid that was already in a week condition.

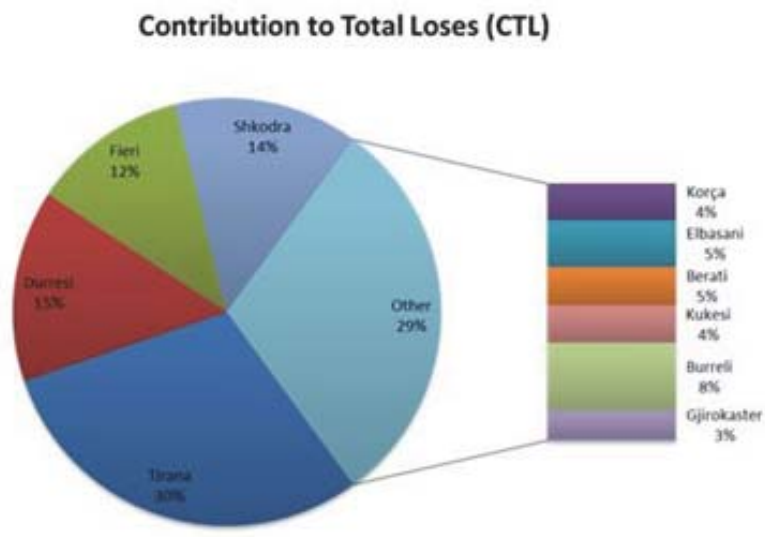

Figure 2. Contribution of Total Loses

\section{Needs of Cooperation between Two Projects: Master Data Cleaning and Management of Loses, for Better Management of Loses.}

The common areas consumption in CEZ management time even now is not properly treated due to not clean data and historical procedure vacuum.

I will go ahead with the comparison of the 2 views the most important concept in CEZ time and need to be even at 
the actual status.

The Situation at Billing System was:

- Approximately 8.4k common area electrometers(EM) were in Billing System

- Mostly common areas light/elevator/water pumps

- There was no clear mark of these EM in Billing System

- The identification was done base on:

- Description field/Name of the Contract/a flag migrated from old system(KP2as suggested by MR)

- There was not being marked any new common area EM since the Billing System was launched.

- It was billed on customers based on the imputed "Consumption" income from MyAvis System(register 3)

- There was no link in Billing System between above listed EM and the customers to be allocated the respective consumption.

- Up to April 2012 CEZ management part had issued bills for all common areas with 240ALL service fee\& TV tariff (until Dec 2012). Part of this cases have the coefficient 0 in order not to double consumption in Billing System and other are with coefficient 1 but blocked for invoice process.

- In some cases these invoices have been requested/accepted and paid by the administration of common area (mainly new buildings- no clear mark in Billing System)

- Collective boxes were not in the system and no link of collective box with Customers.

Situation at the field:

- Missing functionalities in Myavis System (system who recorded online readings from the PDA's read by the readers) to do proper Common Space Device Management and distribution of consumption. (low possibilities to have this feature)

- In most of the collective boxes there were EM for the measurement of the common area and there were case when there were not EM and all can summarized as below:

- Have EM -Have Contracts

- Have EM - Have not Contracts

- Do not have EM- Have contracts

- Do not have EM -Do not have Contract

- In case where the MR can find (calculate) consumption they divided it by no rule to customers of the collective box and send it through MyAvis in a separate register as a calculated consumption (in kWh):

- Since MR had not access to the previous indexes they were keeping previous index in paper at box door.

- There was not an exact procedure for this action and neither any control point for the customers that had been billed and neither for the respective consumption.

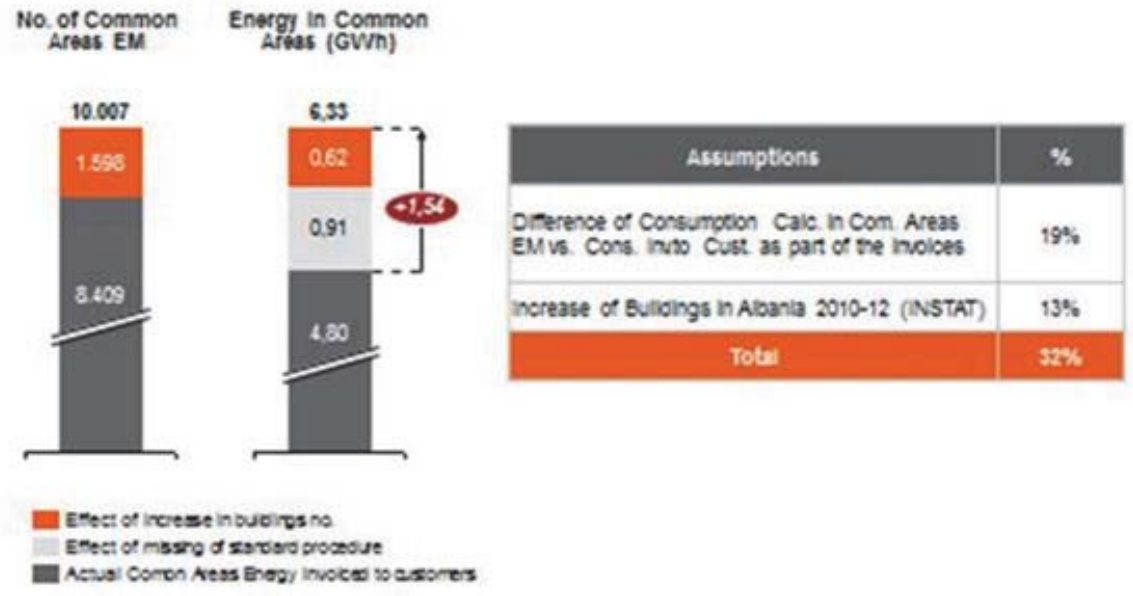

Figure 3. Estimation of the Common Area Consumption. 


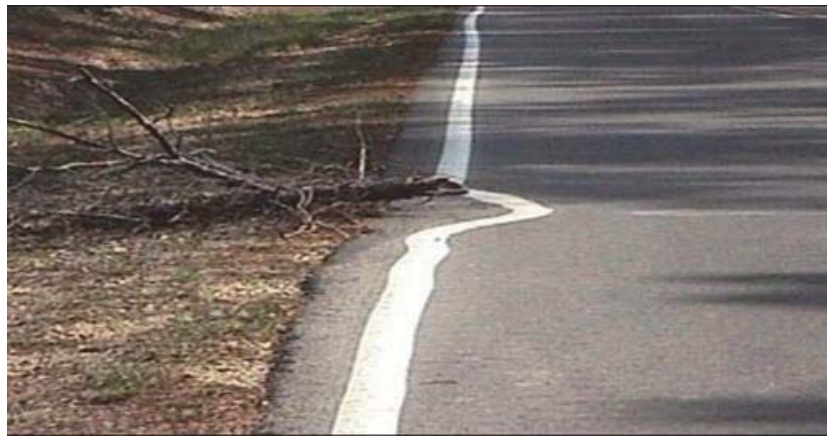

\section{How the Issue Has Been Crossed-over?}

- Common Space issue has been discussed from both BS and MR side during the preparation of Blue Print for Billing System Upgrade (Common Space solution to be included)

- $\quad \mathrm{MR} \& \mathrm{BI}$ have gone through considerable major developments and campaigns however regarding this issue there still remains uncertainties.

- Each part (Billing, MR, MM, AM, NTL) had been trying to do their job but:

- Better coordination and standard procedure needed

- Process and solution to be defined and agreed

- Responsible persons to be assigned

- In Billing System till December 2012 have been applied a solution to exclude from invoicing those identified common areas that have not had any payment since 2007.

- The remaining part was still being invoiced as there might be the possibility that this consumption is being handled by the administrators of common areas

In order to proceeds with the solution there was the need for the clarification of some issues in departmental and top management level.

- Cooperation between all departments is the fundament of the success of the implementation of this solution.

- Lack of common area administration is and will also affect the collection of these common area consumption invoices.

Three steps in which it is more than necessary the cooperation between involved departments would bring a final solutions for actual future issue:

\section{$1^{\text {st }}$ phase.}

Identification of all Common Area cases:

- Certify the common area that have been identified in the Billing System

- Identify and correct what we do not have in Billing System

- Billing System data cleaning process of Common Area

$2^{\text {nd }}$ phase.

Link of customers to respective common area Electrometer

- Find and implement technical solution for linking the customers to respective common areas electrometers (MyAvis/ Billing System).

- In case we have common areas that are administered by single administrator - to be bill the consumption as single invoice (link to a single customer)

- In case when we have common areas with no easily identifiable single owner, - link all respective customers to the common area- bill proportional consumption to the customer as calculated by MR- do not issue invoice for the common area

$3^{\text {rd }}$ phase.

\section{Final Solution Automatize}

- Find and implement technical solution (in Billing System or MyAvis) for the automatic calculation of the consumption of common areas and allocate it to respective customer/s

- Define clear procedure (rules) for the future treatment of the Common Areas Consumption 


\section{Conclusions}

The company is having the expected operational problems according to the results obtained.

The company needs to implement quickly measures in the line of:

- Strengthen the installations to reduce illegal connections

- Increase the reliability of the metering process

- Stabilize the billing process so that customers with proper conditions are kept safe inside the billing cycle.

- Reorganize the operations in order to reinforce the permanent control over the customers.

- Consolidate the energy balance in order to make it a proper tool for loss reduction.

- Ensure the collection in high debt areas by means of firm and forceful actions over the company's assets that avoid creating an unbearable burden for the Albanian energy sector.

The needs of a Quick Wins Project will provides activities that can be quickly implemented and that shall provide quick results to the OSHEE Company.

The urgencies of the company rely on stabilizing the Billing cycle. This is critical and can be done by the company before the proper implementation of the loss reduction plan. For that purpose there is a need for:

- Trust on the data.

- Control the cycle.

- Avoid refusal for the actions.

Quick Wins Project to develop for OSHEE Company needs to be focused on the following:

- Establish a monitoring framework to ensure the information provided by Meter Readers.

- Stabilize the billing anomalies and start constituting a real Guardian of the Process instead of a Fireman Department. Customers start or stop billing energy with no proper control and understanding.

- Introduce the values concept in order to start creating 'friends' within the staff. Today's situation is of total scepticism and lack of consideration for company's meaning.

- Control the energy flow. As of today the control is very weak.

- Start strengthening the meters to make them more reliable and less accessible for 'trickers' the access to the machinery - Today's meters are physically and technically vulnerable and help little to detect irregularities.

Actions to be addressed in Short

- Reorganization of the OSHEE Company

- It is envisaged a full reorganization of the Operational Activities where head responsible of a number of feeders will be in charge of metering, meter reading, irregularities and collection enforcement.

- Clear and transparent objectives shall be assigned to the heads.

- The rest of the organization shall be supportive of this units

- Evaluation of alternative technologies for the management of the commercial cycle in specific cases (Prepayment, Smart Metering, etc.)

- Improvement of regulatory aspects

- There is a need for some regulatory support in order to facilitate the quick recovery of losses and collection. In that sense, we can figure out the following issues:

- Facilitating collective actions for collection when a community has a clear majority of customers in due.

- Allowing the recovery of the non-registered energy in those cases where the irregularity is not due to a company's fault.

- The implementation of the plan shall require specific resources that need to be addressed with the regulator.

\section{References}

Lance A. Irwin, Member, IEEE. Real experience using power quality data to improve power distribution reliability-White Paper, April 2011.

Jerry Jackson. Forthcoming: Future Energy, Second Edition: Improved, Sustainable and Clean Options for our Planet, Elsevier Science; 2 edition (January 7, 2014)

Chapter 28. Smart Grids: An Optimized Electric Power System, Leader and Research Director, Smart Grid Research Consortium.

Smart electric meters, advanced metering infrastructure, and meter communications: Global market analysis and forecasts," Navigant Research, 2013.

Available: www.navigantresearch.com/research/smart-meters

B. Hobbs, S. Jitprapaikulsarn, S. Konda, V. Chankong, K. Loparo, and D. Maratukulam, "Analysis of the value for unit commitment of 
improved load forecasts," IEEE Transactions on Power Systems, vol.14, no.4, pp.1342,1348, Nov 1999.

M. Baran and T. McDermott, "Distribution system state estimation using AMI data, "Power Systems Conference and Exposition, pp. 1-3, Mar, 2009.

World Bank Group Energy Sector. Reducing Technical and Non-Technical Losses in the Power Sector. Background Paper for the World Bank Group Energy Sector Strategy. July 2009.

Soham Ghosh, "Loss Reduction and Efficiency Improvement: A Critical Appraisal of Power Distribution Sector in India", International Journal of Modern Engineering Research (IJMER), Vol.2, Issue.5, Sep-Oct. 2012 pp-3292-3297. 